\title{
Increasing the awareness of overweight among Saudi people using different social media net- works such as Twitter and Snapchat: A Case of PSAU
}

\author{
Anas A. Salameh ${ }^{a^{*}}$ and Anis Ali ${ }^{\mathrm{b}}$ \\ ${ }^{a}$ Department of Management Information Systems, College of Business Administration, Prince Sattam Bin Abdulaziz University, Alkharj, Saudi \\ Arabia \\ ${ }^{b}$ Department of Management, College of Business Administration, Prince Sattam Bin Abdulaziz University, Alkharj, Saudi Arabia

CHRON I CLE ABSTRACT \\ Article history: \\ Received: April 18, 2020 \\ Received in revised format: May \\ 17,2020 \\ Accepted: May 17, 2020 \\ Available online: May 17, 2020 \\ Keywords: \\ $e-W O M$ \\ Customization \\ Saudi Arabia \\ m-healthcare apps \\ Consumer Satisfaction \\ Marketing activities

\begin{abstract}
The development of the internet infrastructure has generated a new phenomenon and lead to some changes in business strategies as it allowed two-way communications among consumers and companies. At present, social media play a key role in communicating information to people around the world and clearly play a vital role in increasing interaction and awareness in an important way. At present, awareness of diseases has disappeared with new methods. Social networking sites like Twitter, Snapchat and Facebook may change the roles the meanings of information delivery and play a superior in that scope. This research investigates the main factors of the power of social media activities (customization, and e-WOM) towards increasing Saudi's awareness on using mhealthcare apps. The results indicate that customization had a positive and direct influence on increasing Saudi's awareness towards using m-healthcare apps (Brand Awareness). e-WOM had a positive and direct influence on increasing Saudi's awareness toward using m-healthcare apps (brand awareness), confirming that the power of social media activities was an imperative contributor to brand equity (brand awareness).
\end{abstract}

\section{Introduction}

Social media, which include online channels for sharing and participating in a variety of activities, represent an increasingly important way for brands to communicate with attractive audience segments (Murdough, 2009). As everybody notices, we can see that using social media Web sites are among the most common activities of today's children and adolescents. Any Web site that allows social interaction is considered a social media such as Facebook, Snapchat, and Twitter (Bißmeyer et al., 2011). The statistics shows that few of Saudi that take care about the overweight disease's problems, and there are few studies in general specially in Saudi Arabia. Since the power of social media activities factors plays a vital role in sending effective data to customers, so, that will attract them to stay engaging with the services offered by e-brands, products, and brands of mobile healthcare apps evaluated by the digital audiences who spent a long-time exploring different internet pages. Studying the issues focusing on the importance of social media to increase the awareness about diseases and how to treat them among Saudi is a very important and crucial issue (Alanzi et al., 2018; Alsamydai et al., 2018). Thus, assessing awareness of the brand will help to increase electronic brand equity for the long-term period. Some indicator factors can measure the mobile healthcare brands for instance subscriptions, repeat visitors, bounce rates, social likes, and the times spent on site. The study on the impact of the power of social media activities on brand equity (brand awareness) still rare. Thus, this study aims to 
investigate the factors of using social media on increasing the awareness about the overweight disease among Saudi. Moreover, the purpose of the study is to carry out to know the impact of the power of social media activities on increasing awareness towards using m-healthcare apps. The study is carried out to assess the level of responding to the information on social media sites among Saudi citizens. Ultimately, the finding and recommendation of the research will recognize the characteristics of best m-healthcare apps that are able to spread healthcare awareness among Saudi citizens.

\section{Theoretical background}

\subsection{The power of social media activities}

\subsubsection{Customization (personalization)}

Martin and Todorov (2010) explained that any digital initiative strengthens brand and consumer relationship if it provides a platform to connect with brands, and relevance in context of each and every customers requirement of location and activity. Zhu and Chen (2015) explained in their research that no social media can be successful without considering the needs and requirements of the consumers which will enhance the satisfaction. It implies that a social has to customize its features as per the individual requirements of the users. Schmenner (1986) explained in his study the extent customers interact with the service process and how much services are customized as per their needs and requirements. Further he added that quality engagement is much effective than log duration engagement. Schmenner (1986) gave the example of KFC, Mc Donald that are much concerned about the responses of the customers.

H1: Customization has a positive and direct influence on increasing Saudi's awareness towards using m-healthcare apps (Brand Awareness).

\subsubsection{E-word of mouth}

Althunayan et al. (2018) revealed in his study that most of the respondents are using social media to get oral health reasons and twitter, Instagram, and Youtube were used more frequently. The majority of the respondents felt that getting information from the social website was comparatively easy and convenient but communication with experts was great hindrance. ALrukban (2014) reported in his study that the majority of social networking sites were used by young people to get health related information. Only one-third users obtained the wrong health related information while more than two-third checked information from other sources. Alshammari and Alshammari (2017) reported that the majority of the participants were using social websites but there were variations according to the age of the respondents. Most of the participants received health promotion messages and felt positive. Farzin and Fattahi (2018) revealed in their research that electronic- word of mouth through social networking sites was playing a vital role in enhancing consumer trust, consumer engagement and moral obligation. Seo and Park (2018) revealed in their research that trendiness or trolling is the main factor that plays a vital role in SMMAs (social media marketing activities) to convey brand awareness and to build brand image. Shojaee and Azman (2013) revealed that customers engagement, brand exposure and electronic-word-to-mouth had positive effects on brand awareness and most effective factor to retain the customers. They suggested that brands would get benefits from the social media in enhancing the brand awareness and customers would be connected with the brands. Tursunbayeva et al. (2017) summarized in their studies that social media was the means of interaction between media and business. They further added that the social media may be the smart way to provide rapid quality improvement in health sector. They explained that social media of government in public health sector was not performing so efficiently and it required improvements, so based on previous discussions the researcher's hypothesis the following:

$\mathrm{H}_{2}$ : e-WOM has a positive and direct influence on increasing Saudi's awareness towards using m-healthcare apps (Brand Awareness).

\subsection{Brand equity}

\subsubsection{Brand awareness}

Alawamleh et al. (2015) stated that nowadays social media is a way of marketing tools, showing brand identity, raising awareness and reaching the targeted people in less time and cost. Alsinan and Shaman (2017) suggested and indicated that the use of effective methods for increasing awareness using internet and communication technologies should be developed for health issues. Lapointe et al. (2013) stated that social media enables us to create a society of individuals and organizations of a common interest and in healthcare social media provides a platform to similar interest organizations or people conveniently and efficiently. Aburjai et al. (2018) revealed that the source of information from the health specialists and personal is more important than the information available on media or groups. Alnsour and Tayeh (2019) found that the use of social media has a positive impact on brand awareness, brand recall, brand recognition and brand dominance. He Further added that social media is a way to interact with the customers at larger scale, enhancing the knowledge of the customers, and customers stay connected with the banks. Cheung et al. (2019) explained that the social media is playing an important role for understanding 
the influence of social media marketing on communications on brand in different involvement levels. Erdoğmuş and Cicek (2012) revealed that the customers are positively affected by the social media marketing in form of advantageous and relevant content. Godey et al. (2016) found that SMMEs (social media marketing efforts) is governing the behavior of the consumers through positively enhancing the level of brand awareness and brand image. Maria et al. (2019) found that there is a positive and direct relationship between effectiveness of advertising, brand awareness and intention to buy. Ahmad et al. (2016) explored that SMCM (social media content marketing) is making aware about the brand health and due to its continuous interactivity i.e. repeat visitors, subscriptions, social likes, and bounce rates.

\section{Research methodology}

\subsection{Design of sample}

In this study, the researchers used a quantitative approach throughout the research process. This research was conducted at Prince Sattam University hospitals studying (customizations, and e-WOM) variables to meet the research objectives. The data were collected in two months starting from January 2020 to March 2020. A 5-point Likert scale was used and the responses were divided from 1 ("strongly disagree") to 5 ("strongly agree"). As we noticed down here the following Table 1 shows the measurement items used as a source of that research.

Table 1

Measurement items

\begin{tabular}{lll}
\hline Concepts & Variable & Item \\
\hline Social media marketing activity & Customization & $\begin{array}{l}\text { The information that I need can be found in the social media of m-healthcare } \\
\text { awareness app is more customized. } \\
\text { The social media of this m-healthcare awareness app provided the information that } \\
\text { I needed. } \\
\text { The m-healthcare awareness app enables me to control my health performance } \\
\text { progress. } \\
\text { The m-healthcare awareness app records my health activities, and health perfor- } \\
\text { mance. }\end{array}$ \\
& $\begin{array}{l}\text { I will post positive opinions about this m-healthcare awareness app on social me- } \\
\text { dia. }\end{array}$ \\
I will recommend this m-healthcare awareness app using social media. & $\begin{array}{l}\text { I will recommend this m-healthcare awareness app to my social media friends. } \\
\text { I would like to upload content from m-healthcare awareness app on my blog or } \\
\text { micro blog. }\end{array}$ \\
Brand equity & $\begin{array}{l}\text { I am always aware of this m-healthcare awareness app brand. } \\
\text { I am aware of the characteristics of this m-healthcare awareness app. } \\
\text { I can always remember the logo of this m-healthcare awareness app. }\end{array}$ \\
\hline
\end{tabular}

\section{Analysis and findings}

There were 312 questionnaires administered while 265 questionnaires returned only out of which 15 were found incomplete. The response rate of the respondents was 84.93 per cent while the effective rate of response was 72.11 per cent only because only 225 questionnaires were used for the study.

\subsection{Respondents' demographic profile}

The demographic information was collected form the respondents by the administering the questionnaires. In questionnaires certain questions were asked to get the information regarding the using the mobile health care app, their age, gender marital status, level of education, and other related information of using mobile health care apps.

Table 2

Profile of the respondents' demographic factors

\begin{tabular}{|c|c|c|c|}
\hline Construct & Category & Count & Percentage \\
\hline \multirow{4}{*}{$\begin{array}{l}\text { How long have you been using } \mathrm{m} \text {-healthcare } \\
\text { app }\end{array}$} & Less than 1 year & 110 & 48.9 \\
\hline & Between 1 and 3 years & 52 & 23.1 \\
\hline & Between 4 and 6 years & 13 & 5.8 \\
\hline & More than 6 years & 50 & 22.2 \\
\hline Total & & 225 & 100 \\
\hline \multirow{6}{*}{ List of URL of } & Junnah healthcare app & 94 & 41.8 \\
\hline & Ramadan, diabetes and me Healthcare app & 6 & 2.7 \\
\hline & Bupa healthcare app & 18 & 8 \\
\hline & Nesma3k healthcare app & 42 & 18.7 \\
\hline & Medica reminders healthcare app & 53 & 23.5 \\
\hline & Others & 12 & 5.3 \\
\hline \multicolumn{2}{|l|}{ Total } & 225 & 100 \\
\hline
\end{tabular}


Table 2

Profile of the respondents' demographic factors (Continued)

\begin{tabular}{|c|c|c|c|}
\hline Construct & Category & Count & Percentage \\
\hline \multirow{2}{*}{ Gender } & Male & 85 & 37.8 \\
\hline & Female & 140 & 62.2 \\
\hline Total & & 225 & 100 \\
\hline \multirow{6}{*}{ Age } & Below 20 years & 23 & 10.2 \\
\hline & Between 21 and 25 years & 92 & 40.9 \\
\hline & Between 26 and 30 years & 49 & 21.8 \\
\hline & Between 31 and 35 years & 30 & 13.3 \\
\hline & Between 36 and 39 years & 18 & 8 \\
\hline & More than 40 years & 13 & 5.8 \\
\hline Total & & 225 & 100 \\
\hline \multirow{3}{*}{ Highest level of education } & Diploma & 23 & 10.2 \\
\hline & Bachelor's degree & 173 & 76.9 \\
\hline & Masters or higher & 29 & 12.9 \\
\hline \multirow[t]{2}{*}{ Total } & & 225 & 100 \\
\hline & Student only & 73 & 32.4 \\
\hline \multirow[t]{2}{*}{ Status } & Employee only & 32 & 14.2 \\
\hline & Both & 120 & 53.4 \\
\hline Total & & 225 & 100 \\
\hline
\end{tabular}

As reflected by the Table 2, there were 37.8 percent male participated in the survey while 62.2 percent females contributed to facilitate the information for the study. The study revealed that 48.9 percent of the respondents used mobile healthcare app less than one year, 23.1 percent between 1 to 3 years, 5.8 percent between 4 to 6 years, and 22.2 percent of the respondents were using mobile health care app for more than 6 years. It can be concluded that the majority of the respondents were using the mobile health care app during the last one year to get health benefits. Junnah healthcare app, Medica reminders healthcare app, and Nesma3K Healthcare app were the most applied apps among the Saudis. Junnah health care app, Medica reminders healthcare app, and Nesma3K Healthcare were serving 41.8 percent, 23.5 percent, and 18.7 percent to the respondents, respectively. The health care apps in Saudi Arabia was mostly used by youths of 21 to 25 years of age. The health acre apps were the lowest means of spreading awareness among the respondents who were 36 to 39 years of age group ( 8 per cent) or above the 40 years of age group (5.8). The health care apps are frequently used by the respondents who are holding the bachelor degree (76.9 percent) while the trend of using the by the diploma holders (10.2 percent) and masters or higher degree holders are similar (12.9 percent). The health care apps are very famous among the respondents whose status was student and employee both (53.4 percent) while students (32.4 percent) was using more than the employees (14.2 percent).

\subsection{Descriptive statistics of the constructs}

A descriptive analysis was conducted to epitomize the data to get the general status of the constructs. Table 3 presents the mean, standard deviation, minimum and maximum of the constructs. The average mean of all the constructs was in between 3.455 and 3.642, and standard deviations were found between 0.059 to 0.066 .

Table 3

The descriptive statistics of the constructs

\begin{tabular}{|c|c|c|c|c|c|c|}
\hline \multirow{2}{*}{ Constructs } & \multirow{2}{*}{$\mathrm{N}$} & \multirow{2}{*}{ Minimum } & \multirow{2}{*}{ Maximum } & \multicolumn{2}{|c|}{ Mean } & \multirow{2}{*}{ Std. Deviation } \\
\hline & & & & Statistic & Std. Error & \\
\hline Customization & 225 & 1 & 5 & 3.455 & 0.059 & 0.885 \\
\hline e-WOM & 225 & 1 & 5 & 3.46 & 0.065 & 0.979 \\
\hline $\begin{array}{l}\text { Increasing Saudis' awareness towards using m- } \\
\text { healthcare apps (brand awareness) }\end{array}$ & 225 & 1 & 5 & 3.642 & 0.066 & 0.995 \\
\hline
\end{tabular}

\subsection{The prediction quality of the model}

As explained by the predictor constructs the coefficient of determination $\left(\mathrm{R}^{2}\right)$ of the endogenous constructs is responsible for the variance of a particular constructs. The degree of the $\mathrm{R}^{2}$ for the endogenous variables was applied as a pointer of prognostic power of the mode. Predicting model validity is performed by using the technique of reuse of samples which was propounded by Stone (1975) and Geisser (1975). Wold advocated that this technique is suitable and the PLA model must be adopted (Göts et al., 2011). Wold (1983) in this perspective argued that for this technique to perfectly fit, the PLS modeling approach must be adopted (Göts et al., 2011). To ascertain the predictive relevance of the model (Chin, 1998b; Fornell \& Cha, 1994; Geisser, 1975; Stone, 1975) the Stone-Geisser's non-parametric test is suitable. This can be achieved through the employment of the blindfolding procedure as contained in Smart-PLS 3.0 package. The procedure of blindfolding is scheduled for the purpose of removing some of the data and handling it as missing values to estimate the parameters. Ultimately, general cross-validating metric of Q2 is to be provided by the blindfolding process. Normally, Q2 has different forms which the researcher can obtain 
easily depending on the form of prediction that is desired, for example, using underlying LVs for the prediction of data points a cross-validated communality Q2 can be obtained. LVS is used to predict the block in question and the data points are obtained when cross validated redundancy Q2 is the output. Fornell and Cha (1994) explained that the model has predictive validity power if the value of redundant communality is found to be more than 0 for all endogenous constructs, otherwise, the predictive relevance of the model cannot be found.

Table 4

Predictive quality of the model

\begin{tabular}{lcccc}
\hline Construct & Variable Type & R Square & $\begin{array}{c}\text { Cross-validated } \\
\text { Redundancy }\end{array}$ & $\begin{array}{c}\text { Cross-validated } \\
\text { Communality }\end{array}$ \\
\hline $\begin{array}{l}\text { Increasing Saudis' awareness towards using m- } \\
\text { healthcare apps (brand awareness) }\end{array}$ & Endogenous & 0.532 & 0.405 & 0.619 \\
\hline
\end{tabular}

As illustrated in above Table 4, the results of the study related to the prediction quality of the model were the cross-validated redundancy for the Increasing Saudi's Awareness Towards using m-healthcare apps (Brand Awareness) having values of 0.405. The value in the study is more than zero pointing an adequate predictive validity of the model based on the criteria suggested by Fornell and Cha (1994).

\subsection{The whole model of Goodness of fit}

PLS SEM has only one measure of GoF like the CBSEM approach. A global fit measure for PLS path modeling is the geometric mean of the average community and average of $\mathrm{R}^{2}$ for the endogenous constructs (Tenenhaus et al., 2005). For both outer and inner models, the GoF measure accounts for the variance extracted. To support the validity of the PLS model, the GoF values can be estimated based on the procedures laid down by Calabrese and Wetzels (2009).

$$
\text { Formula: } \mathrm{GoF}=\sqrt{\left(\mathrm{R}^{2} * \mathrm{AVE}\right)}
$$

For the purpose of this study, the obtained GoF value was 0.575 as calculated by the formula:

(1) $\mathrm{GoF}=\sqrt{(0.532 * 0.622)}=0.575$

As suggested by suggested by Calabrese and Wetzels (2009), baseline values of GoF ( small $=0.1$, medium $=0.25$ and large $=0.36$ ) can be considered as standard for comparison and this reveals that GoF model tends towards large.

\subsection{Hypotheses testing procedures}

The hypothesized relationships of the model as we noticed in Fig. 1 were tested by performing the PLS algorithm after completing the necessary procedures when the coefficient path were generated (depicted in Fig. 2 and Fig. 3).

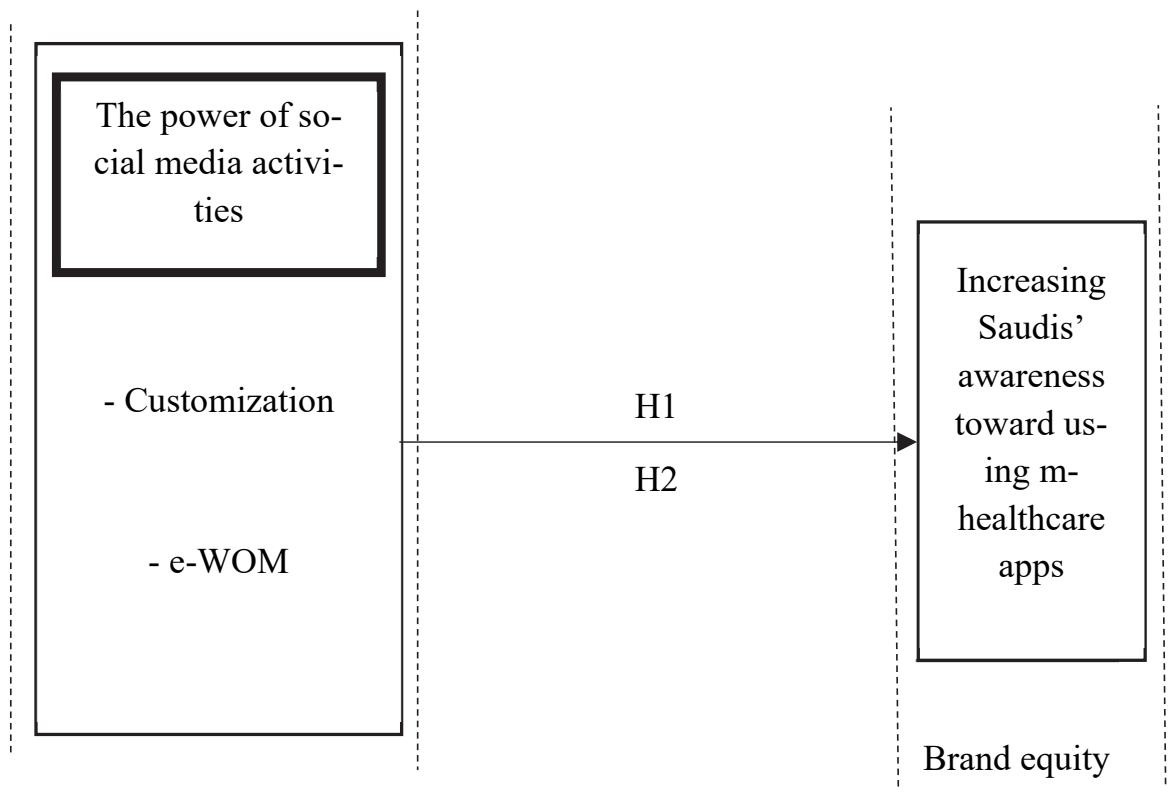

Fig. 1. Research framework 


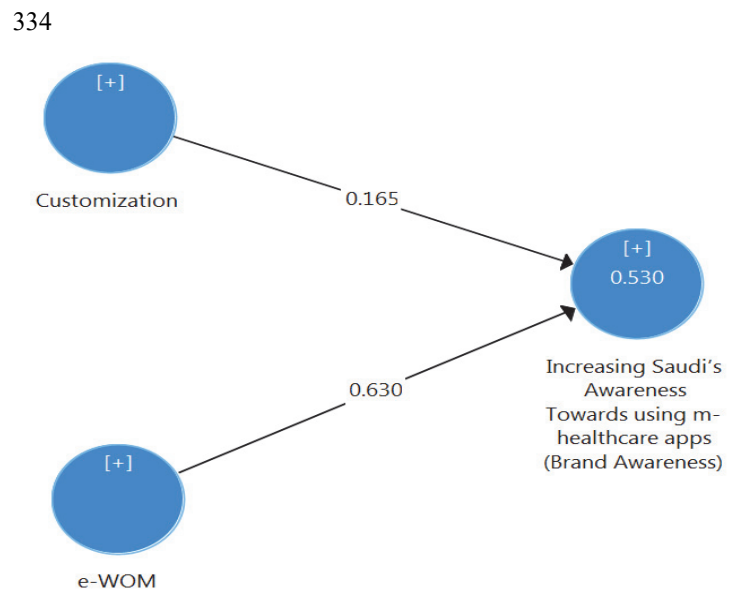

Fig. 2. Path model results

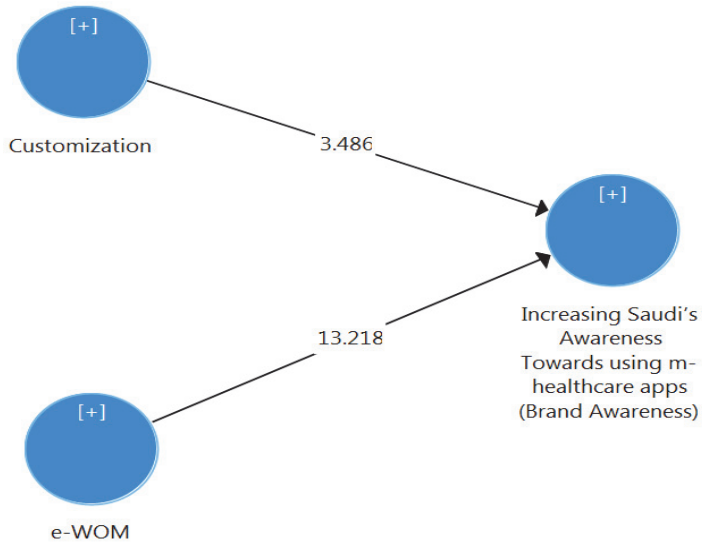

Fig. 3. Path model significance results

In concluding that the path coefficients are statistically significant or not bootstrapping techniques were used (as contained in the Smart-PLS 3.0). The t-values were generated with the aid of the bootstrapping that follow each path coefficient and the pvalues were found (as in Table 5). A significant relationship was revealed by the influence of (customization, and e-WOM) on the increasing Saudi's awareness towards using m-healthcare apps (Brand Awareness).

Table 5

Path coefficient of the research hypotheses the results of inner structural model

\begin{tabular}{|c|c|c|c|c|c|c|}
\hline Hypotheses Relationship & $\begin{array}{c}\text { Path } \\
\text { Coefficient }\end{array}$ & $\begin{array}{c}\text { Sample } \\
\text { Mean (M) }\end{array}$ & $\begin{array}{l}\text { Standard De- } \\
\text { viation } \\
\text { (STDEV) }\end{array}$ & $\mathrm{T}$ Values & P Values & Decision \\
\hline $\begin{array}{l}\text { Customization } \rightarrow \text { Increasing Saudi's Aware- } \\
\text { ness Towards using m-healthcare apps } \\
\text { (Brand Awareness) }\end{array}$ & $0.160 * * *$ & 0.165 & 0.051 & 3.155 & 0.002 & Supported \\
\hline $\begin{array}{l}\text { e-WOM } \rightarrow \text { Increasing Saudi's Awareness } \\
\text { Towards using m-healthcare apps (Brand } \\
\text { Awareness) }\end{array}$ & $0.635 * * *$ & 0.633 & 0.048 & 13.303 & 0.000 & Supported \\
\hline
\end{tabular}

Significant at $*: \mathrm{p}<0.1 ; * *: \mathrm{p}<0.05 ; * * *: \mathrm{p}<0.01$

There is a positive effluence of customization (CUST) and e-world of mouth (e-WOM) with the parameters $(\beta=0.160, \mathrm{t}=$ 3.155, and $\mathrm{p}<0.01)$ and $(\beta=0.635, \mathrm{t}=13.303$, and $\mathrm{p}<0.01$ and $\mathrm{p}<0.01)$ on increasing Saudi's Awareness Towards using $\mathrm{m}$-healthcare apps (Brand Awareness), respectively. As shown in table above 5, the impact of exogenous variables on the endogenous variables was obtained using the following formula:

Effect Size $=$ Effect $\operatorname{size}(f)=\frac{R_{\text {incl }}^{2}-R_{\text {excl }}^{2}}{1-R_{\text {incl }}^{2}}$

As depicted in Table 6, the effect size of all exogenous variables as depicted in Table V was between 0.040 and 0.637 for all variables and, this range described, as per Cohen's (1992) criterion, that all values were less than 0.1 and therefore can be explained as small. In this research PLS-SEM was used by the researchers as the major analysis technique since the assumption of multivariate normality of the data was not fulfilled. The hypothesized relationships were tested by establishing the validity and reliability of the measurement model. The structural model was examined and the results were reported in details (available in Table 6 \& Table 7), respectively.

\section{Table 6}

The effect size of exogenous constructs

\begin{tabular}{llll}
\hline Endogenous Construct & Exogenous Constructs & Effect Size & Result \\
\hline Increasing Saudi's Awareness Towards using m- & Customization & 0.040 & Small Effect \\
healthcare apps (Brand Awareness) & e-WOM & 0.637 & Large Effect \\
\hline
\end{tabular}

Table 7

Summary of the results

\begin{tabular}{clc}
\hline Hypothesis & Hypothesized path & Decision \\
\hline H1 & $\begin{array}{l}\text { Customization have a positive and direct influence on Increasing Saudi's Awareness } \\
\text { Towards using m-healthcare apps (Brand Awareness). }\end{array}$ & Supported \\
H2 & $\begin{array}{l}\text { e-WOM have a positive and direct influence on Increasing Saudi’s Awareness To- } \\
\text { wards using m-healthcare apps (Brand Awareness). }\end{array}$ & Supported \\
\hline
\end{tabular}




\section{Conclusion and implications}

This study discovered the effects of the power of social media activities - customization and e-WOM on one type of brand equity - increasing Saudi's awareness toward using m-healthcare apps (brand awareness). The researchers summarized the results of this study as follows. Customization had a positive and direct influence on increasing Saudi's awareness towards using m-healthcare apps (Brand Awareness). e-WOM had a positive and direct influence on increasing Saudi's awareness toward using m-healthcare apps (brand awareness), confirming that the power of social media activities was an imperative contributor to brand equity (brand awareness).

This study presented the vital and positive impact of the power of social media activities on brand equity, it is in line with other brand equity studies (Godey et al., 2016; Seo, \& Park, 2018). Besides, they focus more on the level of customer response and did not focus on brand equity and how to increase awareness among online consumers. So, this study concentrated more on how the power of social media activities affect awareness of Saudi's about healthcare app and how they can use it to solve their illness issues.

From a managerial spot of opinion, the foremost contributions involve the subsequent points. The study recognized the power of social media activities content dimensions of customization, and e-WOM, all of that contribute for development of brand equity expressing the brand awareness. Thus, customization and e-WOM are relevant to consumers. According to the previous findings, any kind of social media marketing strategy should have particular consideration to customize the content and tracking the consumer behavior using cookies tool to be able to understand customer preferences and build a strong relationship with them to encourage them to tell others about their experiences on social media sites "e-WOM". Ordinarily speaking, brands should, accordingly, attempt to promote these features on their social media sites.

\section{Limitations and future research}

The limitations of this study and the recommended direction for future studies are as follows. First, the unit for this research was limited to Saudi patients. Further and general studies combining a broader spectrum of patients would provide for added significant generalization of the findings. Second, although this research empirically confirmed that the power of social media activities had a positive effect on brand equity (brand awareness), the negative influence on knowledge or the managerial success of businesses was not addressed. Future investigations recognizing these limitations would offer valuable information not just to the hospitals, or even to medicine companies but additionally to marketers in another area who attempt clarifications for social media marketing policies and decision making.

\section{Acknowledgements}

The authors would like to thank the Deanship of Scientific Research, Prince Sattam Bin Abdulaziz University, Alkharj, Saudi Arabia, for providing financial support to complete this project (Project No: 2019/02/11356)

\section{References}

Alawamleh, M., Bani Ismail, L., Shashaa, A., (2015). The era of social media in the middle east. Organisational Studies and Innovation Review, 1(1), 1-9.

Alshammari, A. S., \& Alshammari, H. S. (2017). Use of social media and other electronic media in health education and health promotion: Pilot Study. The Egyptian Journal of Hospital Medicine, 69(6), 2658-2662.

Ahmad, N. S., Musa, R., \& Harun, M. H. M. (2016). The impact of social media content marketing (SMCM) towards brand health. Procedia Economics and Finance, 37(16), 331-336.

Alanzi, T. M., \& Alshahrani, B. (2018). Use of social media in the Department of radiology at Johns Hopkins aramco Healthcare in saudi arabia. Journal of Multidisciplinary Healthcare, 11, 583-589.

Alsamydai, A., Baqa'in, G., Al-Helli, I., Aladwan, H., Salman, K., Herimi, R., \& Aburjai, T. (2018). The Role of Information Resources on Building Health Awareness -Study Conduct in Amman Jordan, International Research Journal of Pharmacy and Medical Sciences (IRJPMS), 1(6), 44-49.

Alnsour, M., \& Tayeh, Z. A. (2019). Impact of social media use on brand awareness: an applied study on Jordanian banks that uses Facebook. International Journal of Electronic Banking, 1(4), 341-357.

ALrukban, A. (2014). The health related uses of social media among users in Saudi Arabia. International Journal of Medical Science and Public Health, 3(12), 1492-1497.

Althunayan, A., Alsalhi R, \& Elmoazen R (2018). Role of social media in dental health promotion and behavior change in Qassim province, Saudi Arabia. International Journal of Medical and Health Research, 4(2), 98-103.

Alsinan, A., \& Shaman, A. A. (2017). A Study to Measure the Health Awareness of Polycystic Ovarian Syndrome in Saudi Arabia. Global Journal of Health Science, 9(80), 210-219.

Bißmeyer, N., Stübing, H., Schoch, E., Götz, S., Stotz, J. P., \& Lonc, B. (2011, October). A generic public key infrastructure for securing car-to-x communication. In 18th ITS World Congress, Orlando, USA (Vol. 14).

Calabrese, A., \& Wetzels, W. L. (2009). Loan Phonology. Issues and Controversies. John Benjamins, Amsterdam, 1-10. 
Cheung, M. L., Pires, G. D., \& Rosenberger III, P. J. (2019). Developing a conceptual Model for examining social media marketing effects on brand awareness and brand image. International Journal of Economics and Business Research, 17(3), 243-261.

Chin, W. W. (1998). The partial least squares approach to structural equation modeling. Modern Methods for Business Research, 295(2), 295-336.

Cohen, S. M. (1992). in Carcinogenesis. Rational Readings on Environmental Concerns, 167.

Erdoğmuş, İ. E., \& Cicek, M. (2012). The impact of social media marketing on brand loyalty. Procedia-Social and Behavioral Sciences, 58, 1353-1360.

Farzin, M., \& Fattahi, M. (2018). eWOM through social networking sites and impact on purchase intention and brand image in Iran. Journal of Advances in Management Research, 15(2), 161-183.

Fornell, C., \& Cha, J. (1994). Advanced Methods of Marketing Research, ed. RP Bagozzi.

Martin, K., \& Todorov, I. (2010). How will digital platforms be harnessed in 2010, and how will they change the way people interact with brands?. Journal of Interactive Advertising, 10(2), 61-66.

Schmenner, R. W. (1986). How can service businesses survive and prosper. Sloan Management Review, 27(3), 21-32.

Tursunbayeva, A., Franco, M., \& Pagliari, C. (2017). Use of social media for e-Government in the public health sector: A systematic review of published studies. Government Information Quarterly, 34(2), 270-282.

Geisser, S. (1975). The predictive sample reuse method with applications. Journal of the American statistical Association, 70(350), 320-328.

Godey, B., Manthiou, A., Pederzoli, D., Rokka, J., Aiello, G., Donvito, R., \& Singh, R. (2016). Social media marketing efforts of luxury brands: Influence on brand equity and consumer behavior. Journal of Business Research, 69(12), 5833-5841.

Lapointe, L., Ramaprasad, J., \& Vedel, I. (2013, January). Collaborating through social media to create health awareness. In 2013 46th Hawaii International Conference on System Sciences (pp. 792-801). IEEE.

Maria, S., Pusriadi, T., Hakim, Y. P., \& Darma, D. C. (2019). The Effect of Social Media Marketing, Word of Mouth, and Effectiveness of Advertising on Brand Awareness and Intention to Buy. Jurnal Manajemen Indonesia, 19(2), 107-122.

Murdough, C. (2009). Social media measurement: It's not impossible. Journal of Interactive Advertising, 10(5), 94-99.

Seo, E. J., \& Park, J. W. (2018). A study on the effects of social media marketing activities on brand equity and customer response in the airline industry. Journal of Air Transport Management, 66, 36-41.

Shojaee, S., \& Azman, A. B. (2013). An evaluation of factors affecting brand awareness in the context of social media in Malaysia. Asian social science, $9(17), 72$.

Stone, A. A., \& Stromberg, C. D. (1975). Mental health and law: A system in transition. National Institute of Mental Health, Center for Studies of Crime and Delinquency.

Tenenhaus, M., Vinzi, V. E., Chatelin, Y. M., \& Lauro, C. (2005). PLS path modeling. Computational Statistics \& Data Analysis, 48(1), 159-205.

Wold, S., Martens, H., \& Wold, H. (1983). The multivariate calibration problem in chemistry solved by the PLS method. Lecture Notes in Mathematics, 286-293.

Zhu, Y. Q., \& Chen, H. G. (2015). Social media and human need satisfaction: Implications for social media marketing. Business Horizons, 58(3), 335-345.

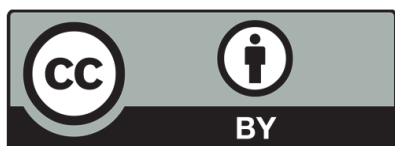

(C) 2020 by the authors; licensee Growing Science, Canada. This is an open access article distributed under the terms and conditions of the Creative Commons Attribution (CC-BY) license (http://creativecommons.org/licenses/by/4.0/). 